Article

\title{
Anion Exchange Membranes Obtained from Poly(arylene ether sulfone) Block Copolymers Comprising Hydrophilic and Hydrophobic Segments
}

\author{
Jun Ha Kim ${ }^{1}$, Mohanraj Vinothkannan ${ }^{2}\left(\mathbb{D}\right.$, Ae Rhan Kim ${ }^{3, *}$ and Dong Jin Yoo ${ }^{1,2,4 * *(1)}$ \\ 1 Department of Energy Storage/Conversion Engineering of Graduate School, Hydrogen and Fuel Cell \\ Research Center, Jeonbuk National University, Jeonju, Jeollabuk-do 54896, Korea; dtd351351351@hanmail.net \\ 2 R\&D Education Center for Whole Life Cycle R\&D of Fuel Cell Systems, Jeonbuk National University, Jeonju, \\ Jeollabuk-do 54896, Korea; vinothkannanram@gmail.com \\ 3 R\&D Center for CANUTECH, Business Incubation Center and Department of Bioenvironmental Chemistry, \\ Jeonbuk National University, Jeonju, Jeollabuk-do 54896, Korea \\ 4 Department of Life Science, Jeonbuk National University, Jeonju, Jeollabuk-do 54896, Korea \\ * Correspondence: canutech@hanmail.net (A.R.K.); djyoo@jbnu.ac.kr (D.J.Y.)
}

Received: 22 December 2019; Accepted: 24 January 2020; Published: 4 February 2020

\begin{abstract}
The anion exchange membrane may have different physical and chemical properties, electrochemical performance and mechanical stability depending upon the monomer structure, hydrophilicity and hydrophobic repeating unit, surface form and degree of substitution of functional groups. In current work, poly(arylene ether sulfone) (PAES) block copolymer was created and used as the main chain. After controlling the amount of NBS, the degree of bromination (DB) was changed in Br-PAES. Following that, quaternized PAES (Q-PAES) was synthesized through quaternization. Q-PAES showed a tendency of enhancing water content, expansion rate, ion exchange capacity (IEC) as the degree of substitution of functional groups increased. However, it was confirmed that tensile strength and dimensional properties of membrane reduced while swelling degree was increased. In addition, phase separation of membrane was identified by atomic force microscope (AFM) image, while ionic conductivity is greatly affected by phase separation. The Q-PAES membrane demonstrated a reasonable power output of around $64 \mathrm{~mW} / \mathrm{cm}^{2}$ while employed as electrolyte in fuel cell operation.
\end{abstract}

Keywords: PAES; Q-PAES; anion conductivity; alkaline stability

\section{Introduction}

As environmental pollution and depletion of fossil fuels become severe problems to world, demand of renewable energy is continuously increasing. Fuel cells, which possess diversified useful advantages include high efficiency, wide range of fuel choices and low/undetectable emission of pollutants, are the conversion devices that change chemical energies into electrical energies. Fuel cells can be categorized into various sorts depending on their operating temperature or electrolyte [1]. Among them, polymer electrolyte fuel cell (PEFC) has received a lot of attention owing to its low operating temperature and high density of energy, quick start up and shutdown times [2]. Despite advantages of PEFC, commercialization is still hampered due to high cost materials i.e., perfluorinated sulfonic acid (PFSA) membrane as electrolyte and noble metals as electrocatalyst. Accordingly, various efforts are being devoted to fabricate alternative fuel cells in order to overcome these drawbacks. Alkaline fuel cell (AFC) is attracting massive attention as one of the replacements owing to the advantages that the oxygen reduction reaction (ORR), an important chemical reaction in the efficiency of fuel cells, is fast in an alkaline environment, which is causing it feasible to use non-noble metal catalysts (like $\mathrm{Ni}$ and $\mathrm{Co}$ ) [3]. 
A large number of studies about the AFC have been conducted in the last decade and a lot of progress has been made. As the initial AFC had used potassium hydroxide $(\mathrm{KOH})$ solution as a liquid electrolyte, problems containing the electrolyte leakage and the precipitation of potassium carbonate $\left(\mathrm{K}_{2} \mathrm{CO}_{3}\right)$ have been found [4]. However, the above problems were solved with the development of solid electrolyte membrane. Various polymer matrix structures such as poly(arylene ether ketone) [5], poly(arylene ether sulfone) (PAES) [6,7], poly(phenylene oxide) [8,9] and poly(vinyl alcohol) $[10,11]$ have been widely investigated. In addition, the stability of diversified of cationic functional groups have been the focus of many efforts, such as trimethyl amine, phosphonium, imidazolium, 1,4-diazabicyclo[2.2.2]octane (DABCO) and so on [12].

Although there is a lot of development of anion exchange membrane (AEM) as mentioned above, some factors of AEM hinder the practical application, which remains a challenge to be improved. There is a disadvantage that hydroxide $\left(\mathrm{OH}^{-}\right)$ions moving through the electrolyte in AEM exhibit low ion conductivity because of low diffusion coefficient when compared to $\mathrm{H}^{+}$in PEFC [13]. In addition, insufficient alkali stability at high $\mathrm{pH}$ conditions interferes with the practical application of AEM [14,15]. Various studies are under way to overcome these weaknesses. Even though the same materials are used, random copolymer and block copolymer which differ in the polymerization process show different physicochemical properties. A well-defined multiblock structure was responsible for interconnected ion transport channels which is indicating the outstanding hydroxide conductivity. It is very important to understand the change of properties according to the morphology of polymers.

In this work, 3,3',5,5'-tetramethylbiphenyl-4,4'-diol which has four bromination site and bis(4-chlorophenyl) sulfone were used for hydrophilic phase. Hydrophobic phase consisted of bisphenol A and decafluorobiphenyl. From these, a well-controlled PAES block copolymer was synthesized. Various membranes were created by adjusting bromination on the synthesized block copolymer. The designed AEMs are characterized by ${ }^{1} \mathrm{H}-\mathrm{NMR}$ and FT-IR. To end, we selected a bicyclic diamine, DABCO, as the diamine to production of novel quaternary ammonium (QA) groups because of its greater structural stability while compared to stabilities of alternate trimethyl ammonium groups.

\section{Experimental}

\subsection{Materials}

3,3'-Tetramethylbiphenyl-4,4'-diol (TMBD, $>98 \%$ ) and decafluorobiphenyl (DFBP, $>98 \%$ ) were purchased from Tokyo Chemical Industries (Tokyo, Japan). N-bromosuccinimide (NBS, 99\%), bis(4-chlorophenyl) sulfone (BCPS, 98\%), anhydrous $N, N$-dimethylacetamide (DMAc, 99.8\%) and anhydrous toluene were procured from Sigma-Aldrich (Seoul, South Korea). 1,4-DABCO, 98\% and bisphenol A was purchased from Alfa Aesar (Seoul, South Korea). Benzoyl peroxide (BPO, >97\%), $\mathrm{K}_{2} \mathrm{CO}_{3}, 99.5 \%$, 1,1,2,2-tetrachloroethane (TCE), methanol, ethanol and acetone were acquired from Daejung reagents (Siheung, South Korea).

\subsection{Synthesis of Quaternized PAES (Q-PAES) Membranes}

\subsubsection{Synthesis of Hydrophilic Precursors}

PAES block copolymer was synthesized as follows. TMBD (9.93 mmol), BCPS (9.03 mmol) and $\mathrm{K}_{2} \mathrm{CO}_{3}$ were mixed in a solution which contains $15 \mathrm{~mL}$ of toluene and $35 \mathrm{~mL}$ of DMAc. The reaction mixture was stirred for $2 \mathrm{~h}$ at $120^{\circ} \mathrm{C}$ under nitrogen atmosphere. Then, the temperature was raised to $150{ }^{\circ} \mathrm{C}$ and kept for $2 \mathrm{~h}$ in order to eliminate the toluene. The temperature was raised to $170{ }^{\circ} \mathrm{C}$ for $45 \mathrm{~h}$ and then cooled down to room temperature (RT). To end, solution was dispensed to $800 \mathrm{~mL}$ co-solvent (acetone/methanol/deionized water, 1:6:1, v/v/v) to recrystallization. The product was collected by filtration and washed several times with methanol and acetone. The solid was dried at $60^{\circ} \mathrm{C}$ under vacuum at least $48 \mathrm{~h}$. 


\subsubsection{Synthesis of Hydrophobic Precursors}

To make the hydrophobic oligomer, bisphenol A ( $8.39 \mathrm{mmol})$, DFBP $(9.23 \mathrm{mmol})$ and $\mathrm{K}_{2} \mathrm{CO}_{3}$ were added in a solution that contains $15 \mathrm{~mL}$ of toluene and $35 \mathrm{~mL}$ of DMAc with a mechanical stirrer. The reaction mixture was stirred for $2 \mathrm{~h}$ at $120^{\circ} \mathrm{C}$ under nitrogen atmosphere. And then, the solution was heated to $150{ }^{\circ} \mathrm{C}$ for remove the toluene for $2 \mathrm{~h}$. The temperature was raised to $180^{\circ} \mathrm{C}$ for $36 \mathrm{~h}$. After that, the reaction mixture cooled to RT then was dispensed into $800 \mathrm{~mL}$ co-solvent (acetone/methanol/deionized water, 1:6:1, v/v/v). White solid was collected by filtration and washed several times with methanol and acetone. The product was dried at $60{ }^{\circ} \mathrm{C}$ under vacuum at least $48 \mathrm{~h}$.

\subsubsection{Synthesis of PAES Block Copolymers}

The block copolymer was synthesized by condensation polymerization using hydrophilic precursor and hydrophobic oligomer. First, hydrophilic precursor (4.34 g), hydrophobic oligomer (3.94 g) and $\mathrm{K}_{2} \mathrm{CO}_{3}$ were added into a round bottom flask. Next, DMAc $(35 \mathrm{~mL})$ was added and the reaction mixture heated at $80{ }^{\circ} \mathrm{C}$. After $6 \mathrm{~h}$, the reaction mixture was cooled and recrystallized by $800 \mathrm{~mL}$ co-solvent (acetone/methanol/deionized water, 1:6:1, v/v/v). Finally, the product was collected by filtration and washed several times with methanol. Scheme 1 exhibits the pictorial expression for synthesis of PAES block copolymer.

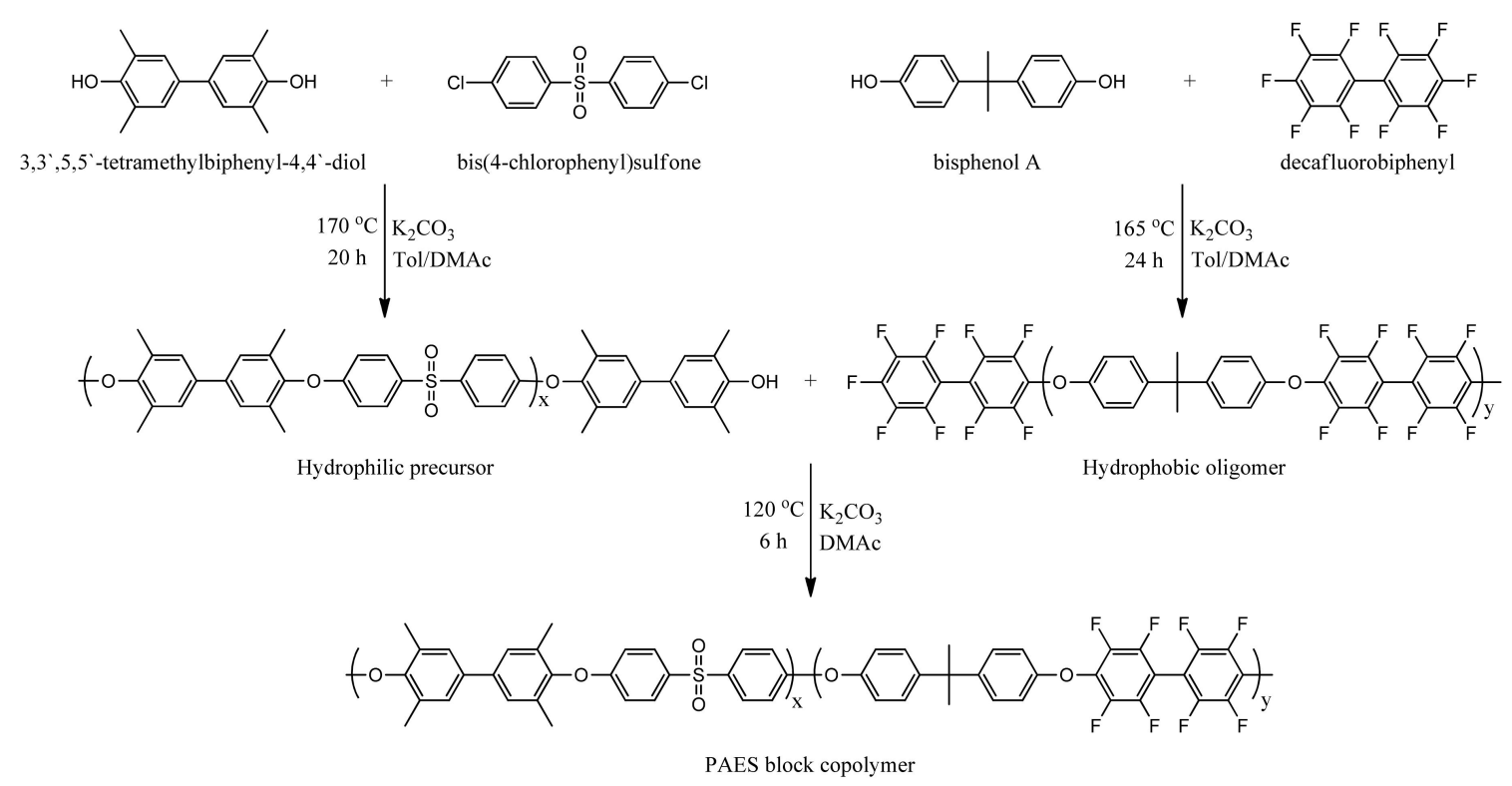

Scheme 1. Synthesis of poly(arylene ether sulfone) (PAES) block copolymer.

\subsubsection{Bromination, Quaternization and Anionization of PAES}

The bromination reaction of PAES was carried out via a free-radical substitution reaction. First, PAES block copolymers $(0.8 \mathrm{~g})$ was dissolved in dried 1,1',2, $2^{\prime}$-tetrachloroethane $(35 \mathrm{~mL})$ in $100 \mathrm{~mL}$ round bottom flaks equipped with mechanical stirrers. The reaction mixture was heated at $60{ }^{\circ} \mathrm{C}$, then NBS and BPO were added. After $6 \mathrm{~h}$, the reaction solution was cooled to RT and recrystallized with ethanol. The obtained solid was washed three times with ethanol and then dried at $60^{\circ} \mathrm{C}$ under vacuum. Afterward, Q-PAES was obtained by performing the quaternization reaction of Br-PAES with DABCO. Br-PAES $(0.5 \mathrm{~g})$ was dissolved in NMP $(5 \mathrm{~mL})$ and then, in addition, DABCO was added to avoid crosslinking. Then, the reaction proceeded for $20 \mathrm{~min}$ at $60^{\circ} \mathrm{C}$; the reaction mixture was cast on a glass plate and dried at $70^{\circ} \mathrm{C}$ under vacuum until the solvent was evaporated. The remaining $\mathrm{DABCO}$ and external substance were removed by immersing the fabricated membrane in methanol at RT for two days. After then the membrane was engulfed in solution of $1 \mathrm{M} \mathrm{KOH}$ for hydroxide 
$\left(\mathrm{OH}^{-}\right)$exchange. The illustration for bromination and quaternization reaction is given in Scheme 2. Corresponding membrane photographs are shown in Figure 1.
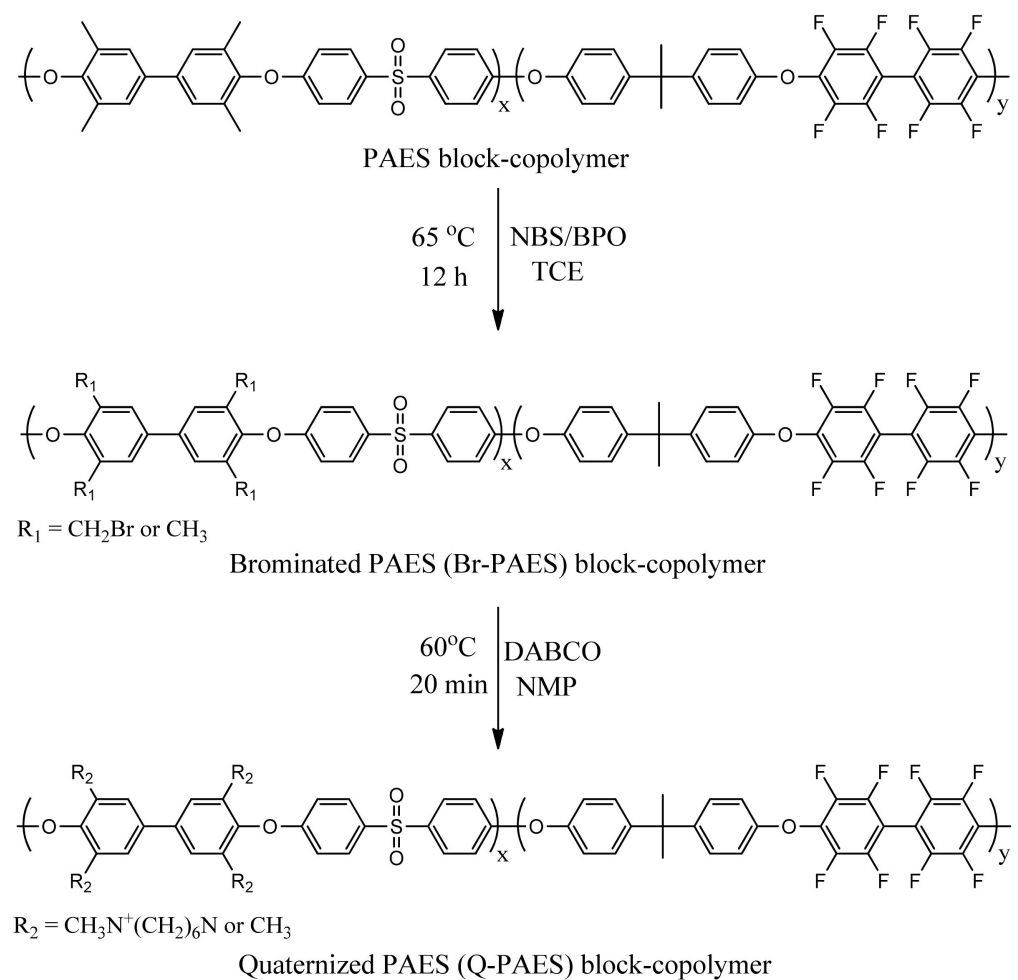

Scheme 2. Bromination and quaternization reaction.
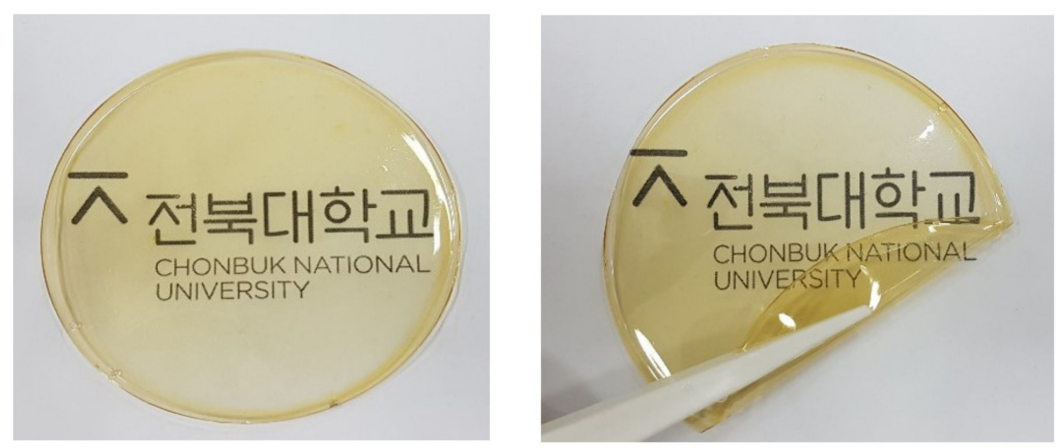

Figure 1. Photographs of membrane.

\section{Characterizations}

Chemical structure of PAES and Br-PAES were analyzed using nuclear magnetic resonance ( ${ }^{1} \mathrm{H}-\mathrm{NMR}$ ) spectroscopy (JNM ECA-600, $600 \mathrm{MHz}, \mathrm{JEOL}$, Peabody, MA, USA) at the Center for University-wide Research Facilities (CURF) at Jeonbuk National University (JBNU). Substitution of functional groups by quaternization reaction was confirmed by Fourier transform infrared spectroscopy (FT-IR) Nicolet Impact 400 (Madison, WI, USA). The molecular weight $\left(\mathrm{M}_{\mathrm{w}}\right)$ of synthesized polymers was measured by using a gel permeation chromatography (GPC) instrument (HLP-8320, Tokyo, Japan). Thermogravimetric analysis (TGA) was performed by employing a TA instrument (Q 50, New Castle, $\mathrm{DE}$, USA) with heating range of $10^{\circ} \mathrm{C} / \mathrm{min}$ in the temperature range of $\mathrm{RT}$ to $800{ }^{\circ} \mathrm{C}$ under nitrogen flow. Thermal stability was evaluated by utilizing differential scanning calorimetry (DSC, Q20, TA Instruments, New Castle, DE, USA) from RT to $250^{\circ} \mathrm{C}$. The temperature increase rate was set to $10^{\circ} \mathrm{C}$ per minute. 
Ion exchange capacity (IEC) of synthesized polymers was determined via back titration method. Q-PAES membranes in $\mathrm{OH}^{-}$form was soaked in $0.5 \mathrm{M} \mathrm{HCl}$ solution for $48 \mathrm{~h}$ separately. After the equilibrium, the $\mathrm{HCl}$ solution was titrated using $0.05 \mathrm{M} \mathrm{NaOH}$ standard solution. IEC was calculated via the given equation $[16,17]$.

$$
\operatorname{IEC}\left(\frac{\text { mequiv }}{\mathrm{g}}\right)=\frac{\mathrm{C}_{\mathrm{HCl}} \times \mathrm{V}_{\mathrm{HCl}}-\mathrm{C}_{\mathrm{NaOH}} \times \mathrm{V}_{\mathrm{X}, \mathrm{NaOH}}}{\mathrm{W}_{\mathrm{dry}}}
$$

where $C$ means the concentration, and $V$ means the volume of solution. $V_{\mathrm{X}, \mathrm{NaOH}}$ is the volume of $\mathrm{NaOH}$ used for back titration.

Water uptake (WU) and swelling ratio (SR) were measured by examining weight and length difference between the dried membrane and soaked the membrane at various temperatures. After measuring the length and weight of the dried membrane, the membrane was immersed in water at appropriate temperature for $24 \mathrm{~h}$ and then the changes in length and weight are measured. The wet membrane was wiped quickly with a tissue and then weighed. The WU and SR were calculated using the following equation respectively. The detailed description for the following equations can be seen in literature $[18,19]$.

$$
\begin{gathered}
\mathrm{WU}(\%)=\frac{\mathrm{W}_{\text {wet }}-\mathrm{W}_{\text {dry }}}{\mathrm{W}_{\text {dry }}} \times 100 \\
\mathrm{SR}(\%)=\frac{\mathrm{L}_{\mathrm{wet}}-\mathrm{L}_{\mathrm{dry}}}{\mathrm{L}_{\mathrm{dry}}} \times 100
\end{gathered}
$$

The hydration of membrane is connected to the water content and refers to the number of water molecules absorbed per ionic group substituted in the anion exchange membrane. The membrane hydration of fabricated Q-PAES was calculated by the below mentioned relation.

$$
\lambda=\frac{\mathrm{WU}(\%) \times 10}{\mathrm{IEC} \times 18}
$$

Atomic force microscopy (AFM) was performed to study the phase separation properties of the Q-PAES membranes. AFM examines topographical changes that occur when a tiny probe is in contact with the surface of the membranes. Nanoscope V multimode 8 AFM was employed as an analytical device for surface rendering process.

Ion conductivity is widely recognized as an essential property for evaluating the performance of a polymer electrolyte membrane because it can compare and predict how much channels are formed to transfer or conduct ions inside the membrane. For this purpose, a Bekk-Tech conductivity test cell and a PGZ 301 dynamic EIS voltammeter were used. The ion conductivity was calculated from the resistance of the membrane, and the relation is as follows.

$$
\sigma=\frac{\mathrm{L}}{\mathrm{R} \times \mathrm{W} \times \mathrm{T}}
$$

$\sigma$ is the ion conductivity $(\mathrm{mS} / \mathrm{cm}), L$ is the ion cross length $(\mathrm{cm}), R$ is the resistance between the two electrodes $(\Omega), W$ is the width $(\mathrm{cm})$, and $T$ is the thickness $(\mathrm{cm})$.

The chemical stability of the AEM plays a significant role in the alkaline operating environment of AFCs. The prepared Q-PAES tested for alkali stability by immersing the membrane in $1 \mathrm{M} \mathrm{KOH}$ solution at $60{ }^{\circ} \mathrm{C}$ for $1000 \mathrm{~h}$, and the quantity of remaining functional groups was measured by ${ }^{1} \mathrm{H}-\mathrm{NMR}$ analysis. 


\section{Result and Discussion}

\subsection{GPC}

PAES block copolymers were created by nucleophilic substitution reaction between the hydrophilic precursors and hydrophobic oligomers. The $M_{\mathrm{W}}$ of the synthesized hydrophilic precursor, hydrophobic oligomer and PAES block copolymer was measured by GPC, and results are given in Table 1 . $\mathrm{M}_{\mathrm{W}}$ of the synthesized PAES block copolymer was measured to be $129.9 \mathrm{kDa}$, and it was confirmed that the multiblock copolymer was successfully synthesized.

Table 1. Molecular weight and PDI of polymers.

\begin{tabular}{cccc}
\hline Polymer & $\boldsymbol{M}_{\mathbf{n}}{ }^{\mathbf{a}}(\mathbf{k D a})$ & $\boldsymbol{M}_{\mathbf{w}}{ }^{\mathbf{b}} \mathbf{( k D a )}$ & PDI $^{\mathbf{c}}\left(\boldsymbol{M}_{\mathbf{w}} / \boldsymbol{M}_{\mathbf{n}}\right)$ \\
\hline Hydrophilic precursor & 5.5 & 18.3 & 3.3 \\
Hydrophobic precursor & 4.2 & 10.3 & 2.4 \\
PAES block copolymer & 19.2 & 129.9 & 6.7 \\
${ }^{\text {a }}$ Number average molecular weight; ${ }^{\mathrm{b}}$ weight average molecular weight; ${ }^{\mathrm{c}}$ polydispersity index.
\end{tabular}

\section{2. ${ }^{1} \mathrm{H}-\mathrm{NMR}$}

After completely drying the synthesized PAES block copolymer, a bromination reaction was performed using NBS and BPO to synthesize Br-PAES. Since bromination proceeds through sensitive radical reactions, it was taken place under nitrogen atmosphere [20]. By following this procedure, various polymers with different degrees of bromination reaction were synthesized by controlling the equivalent of NBS. Afterwards, Br-PAES was dissolved in NMP solvent and subjected to quaternization using DABCO in order to obtain Q-PAES, and to introduce ionic functional groups into the polymer. Q-PAES was transferred from Br-form into $\mathrm{OH}$-form in $1 \mathrm{M} \mathrm{KOH}$ for various properties and performance evaluation. In order to evaluate the structural properties of the synthesized polymer ${ }^{1} \mathrm{H}-\mathrm{NMR}$ spectrum was measured. The ${ }^{1} \mathrm{H}-\mathrm{NMR}$ results of PAES and Br-PAES in Figure 2 show that the peak $H_{\mathrm{a}}$ for the bromination reaction appears at $2.1 \mathrm{ppm}$. The aromatic protons located in the benzene ring varied between 6.8 and $7.9 \mathrm{ppm}$ this is based on the observed peaks of $H_{\mathrm{f}}, H_{\mathrm{c}}$, and $H_{\mathrm{e}}$ at $7.2 \mathrm{ppm}$ and $6.9 \mathrm{ppm}$ respectively. $H_{\mathrm{d}}$, on the other hand, was found at $7.8 \mathrm{ppm}$ [21-23]. $H_{\mathrm{c}}$ and $H_{\mathrm{e}}$ are found in the high field because the neighboring carbon is substituted by electron donor, and $H_{\mathrm{d}}$ is found in the low field due to the neighboring carbon is substituted by aliphatic carbon chains. It can be seen that ${ }^{1} \mathrm{H}-\mathrm{NMR}$ of Br-PAES shows a proton peak of a bromo methylated methyl group $\left(-\mathrm{CH}_{2} \mathrm{Br}\right)$ at $4.3-4.4 \mathrm{ppm}$, which was not found in PAES polymer. This proves that the bromo methylation reaction proceeded properly. The abovementioned peaks were used to calculate the degree of bromination (DB) by following the equation. The amount of NBS was adjusted to control the degree of bromo methylation, and it can be seen that the peak of 4.3-4.4 ppm increases as the amount of NBS increases. Furthermore, it also confirmed from the size of the $\mathrm{H}_{\mathrm{a}}$ peak appears at $2.1 \mathrm{ppm}$ accordingly.

$$
\mathrm{DB}(\%)=\frac{\left[\mathrm{A}\left(\mathrm{H}_{\mathrm{a}}\right)-\mathrm{A}\left(\mathrm{H}_{a^{\prime}}\right)\right]}{\mathrm{A}\left(\mathrm{H}_{a}\right)} \times 100
$$




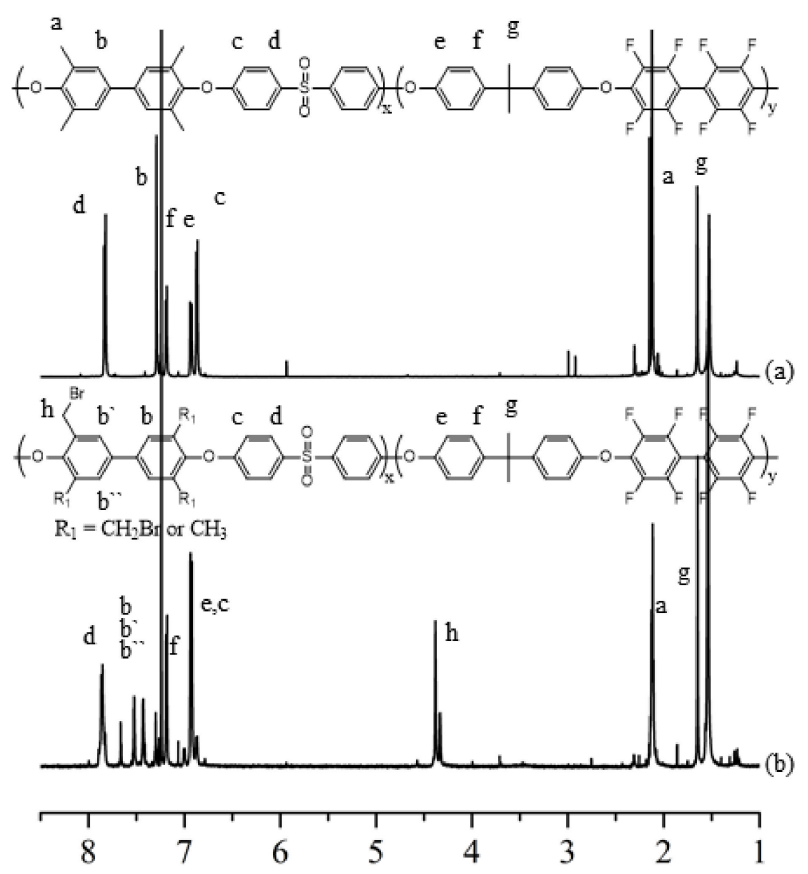

Chemical shift (ppm)

Figure 2. ${ }^{1} \mathrm{H}-\mathrm{NMR}$ of (a) PAES, (b) Br-PAES.

In the above formula, $\mathrm{A}\left(H_{\mathrm{a}}\right)$ denotes the integrated area of $H_{\mathrm{a}}$ peak of PAES polymer, and $\mathrm{A}\left(\mathrm{H}_{\mathrm{a}^{\prime}}\right)$ denotes the integrated area of $H_{\mathrm{a}}$ peak of Br-PAES. Therefore, it was calculated by the area difference between proton peaks in the non-brominated polymer and the brominated polymer. As the DB of polymer increased, the peak area at $2.1 \mathrm{ppm}$ became smaller, while the peak area at $4.3-4.4 \mathrm{ppm}$ was increasing (Figure 3).
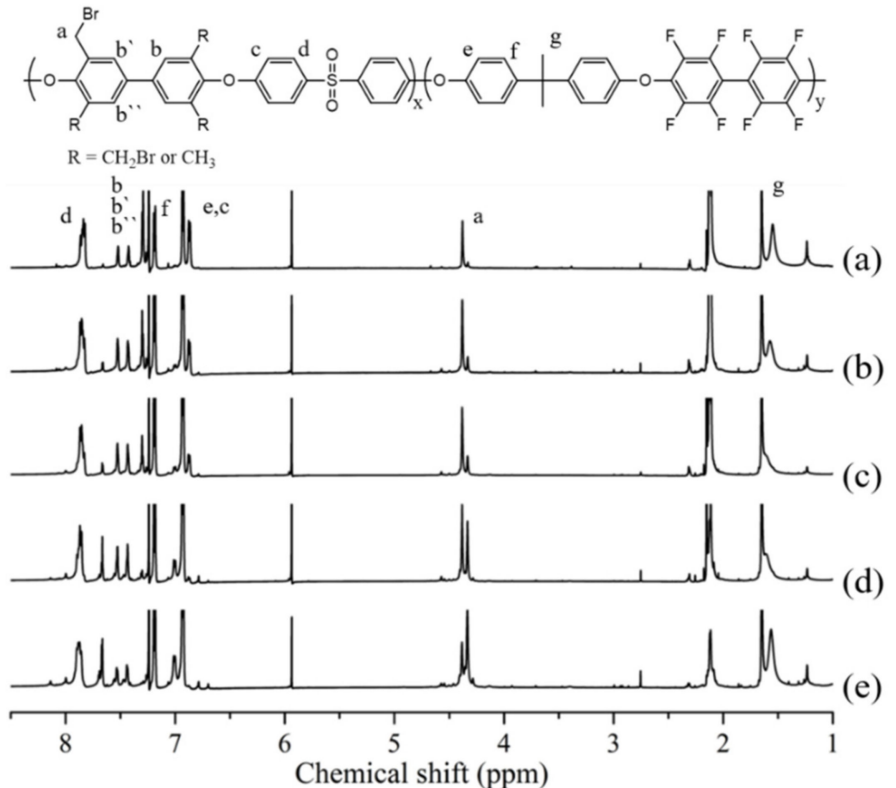

Figure 3. ${ }^{1} \mathrm{H}-\mathrm{NMR}$ of (a) Br-PAES-10\%, (b) Br-PAES-20\%, (c) Br-PAES-30\%, (d) Br-PAES-40\%, (e) Br-PAES-50\%. 


\subsection{FT-IR}

The FT-IR spectra were obtained to examine the bromination reaction and quaternization reaction of the synthesized polymer. The results are shown in Figure 4. Absorption of the peaks at 1587 and $1483 \mathrm{~cm}^{-1}$ were common for all three polymers, PAES, Br-PAES, and Q-PAES which due to the existence of $\mathrm{C}=\mathrm{C}$ bonds. In addition, the peaks of $\mathrm{S}=\mathrm{O}$ and $\mathrm{C}-\mathrm{O}$ bonds were found at 1154 and $1016 \mathrm{~cm}^{-1}$, respectively. The observed peak at $572 \mathrm{~cm}^{-1}$ was due to stretching vibration of C-Br bond. The absorption peak at $572 \mathrm{~cm}^{-1}$ was attributed to the stretching vibration of $\mathrm{C}-\mathrm{Br}$ bond. In the case of Q-PAES, the presence of peaks at 3360 and $1370 \mathrm{~cm}^{-1}$ were related to bond stretching of $\mathrm{O}-\mathrm{H}$ and the $\mathrm{C}-\mathrm{N}$ thus indicates the reaction proceeded successfully $[24,25]$.

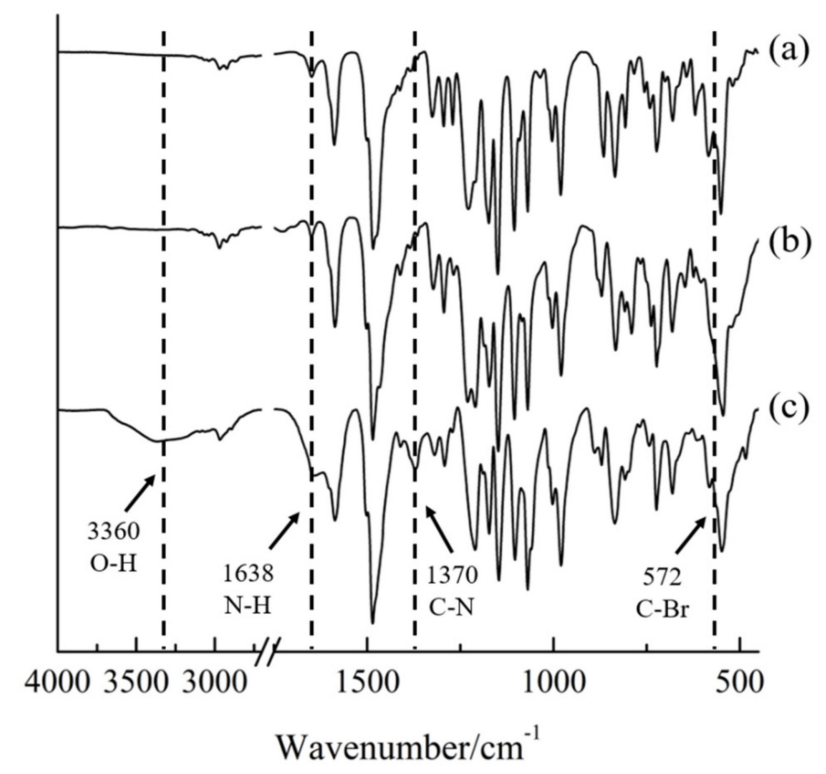

Figure 4. FT-IR of (a) PAES, (b) Br-PAES, (c) Q-PAES.

\subsection{Solubility}

Solubility of prepared PAES, Br-PAES and Q-PAES polymers was measured in order to examine their various assays. The solubility test was conducted at a concentration of $10 \%(w / v)$ at RT. All polymers are didn't dissolved in polar protic solvents include water and methanol. However, it was found that it is dissolved in polar aprotic solvents include chloroform and DMF. Only Q-PAES was partially dissolved in DMSO. This is because the polarity is increased by the quaternary ammonium ion substituted in Q-PAES.

\subsection{Thermal Stability}

TGA was measured to analyze the thermal properties of the synthesized PAES, Br-PAESs, and Q-PAESs polymers (Figure 5a). TGA analysis was measured by heating the samples from room temperature to $800{ }^{\circ} \mathrm{C}$ at the heating rate of $10^{\circ} \mathrm{C}$ per minute in a nitrogen atmosphere. The TGA results of Q-PAESs showed weight loss up to $100{ }^{\circ} \mathrm{C}$, resulting from the elimination of water molecules attached to quaternary ammonium ions. Weight loss at $180-220^{\circ} \mathrm{C}$ is a result of decomposition of the quaternary ammonium group; this phenomenon became higher as the DB value increased [26].

The glass transition temperature $\left(T_{\mathrm{g}}\right)$ of PAES, Br-PAES, and Q-PAES was confirmed by DSC analysis (Figure $5 \mathrm{~b}$ ). In the DSC analysis, the temperature was increased at a rate of $10{ }^{\circ} \mathrm{C}$ per minute in a nitrogen environment, and the presented DSC curves were obtained from the second scan. The $T_{\mathrm{g}}$ values of PAES, Br-PAES, and Q-PAES polymers were at 208,168 and $170{ }^{\circ} \mathrm{C}$, respectively. The Q-PAES is exhibited higher $T_{\mathrm{g}}$ value i.e., because of $\mathrm{DABCO}$, which is bulkier than $\mathrm{Br}$, was introduced into the polymer and interferes with the rotation of $\mathrm{C}-\mathrm{C}$ bond in the main chain. 

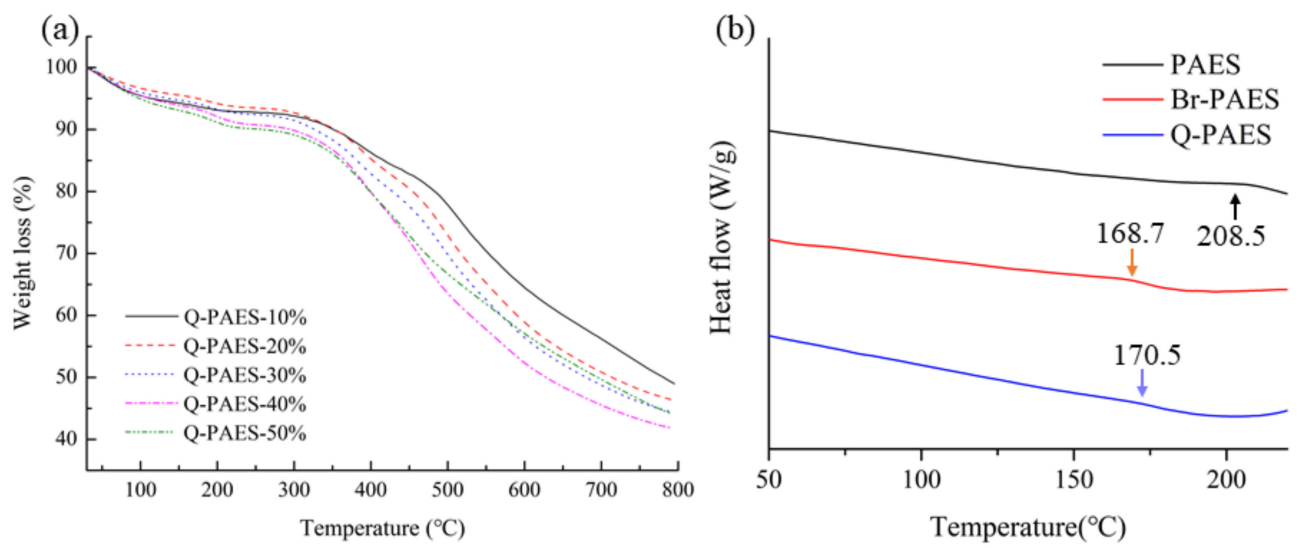

Figure 5. (a) The TGA graph and (b) differential scanning calorimetry (DSC) data of Q-PAESs.

\subsection{IEC, Water Uptake and Dimensional Properties}

The measurement of IEC was proceeded to determine the amount of exchange of hydroxide ions per unit weight of anion exchange membrane. IEC values correlated not only with electrochemical performance but also with water moisture content, expansion rate and mechanical properties of membranes [27]. The IEC value of the synthesized AEMs was measured by following an acid-base titration technique. The measured IEC values of Q-PAES-10\% and Q-PAES-50\% were 1.06 and $1.87 \mathrm{meq} / \mathrm{g}$ respectively. In the AEM, the morphological change of the membrane surface occurs according to the moisture content, which may affect the IEC and the ion conductivity of the membrane. In the case of the AEM comprising of sufficient moisture content, the performance can be improved by the formation of ion channels these in turn improve the transfer of hydroxide ions. However, the water contents in the polymer matrix cause the membrane to expand in volume direction thus decline the mechanical toughness of the membrane and adversely affect its durability. Therefore, it is important to control the water uptake behavior of the membranes. The synthesized Q-PAES membrane was engulfed in $1 \mathrm{M} \mathrm{KOH}$ for $48 \mathrm{~h}$, and then pretreated by dipping in $48 \mathrm{~h}$ in distilled water. The water content and expansion rate of various Q-PAES membranes were measured at the temperature ranges of 30, 50, 70 and $90^{\circ} \mathrm{C}$ (Figure 6a). As the DB of the polymer increased, the hydrophilic part of the membrane increased, which tended to absorb water molecules rapidly. At $90{ }^{\circ} \mathrm{C}$, Q-PAES- $10 \%$ showed $40.9 \%$ water moisture content, whereas Q-PAES- $50 \%$ showed higher value of $74.1 \%$. Hydrated water also showed higher value as $\mathrm{DB}$ value increased. The expansion rate also followed the similar pattern to the water content rate (Figure $6 \mathrm{~b}$ ). At $90{ }^{\circ} \mathrm{C}$, the expansion rate of Q-PAES- $10 \%$ was as low as $9.1 \%$, but the Q-PAES- $50 \%$ was expanded by $29.6 \%$, thereby confirming that the membrane stability was drastically lowered as the DB increased.
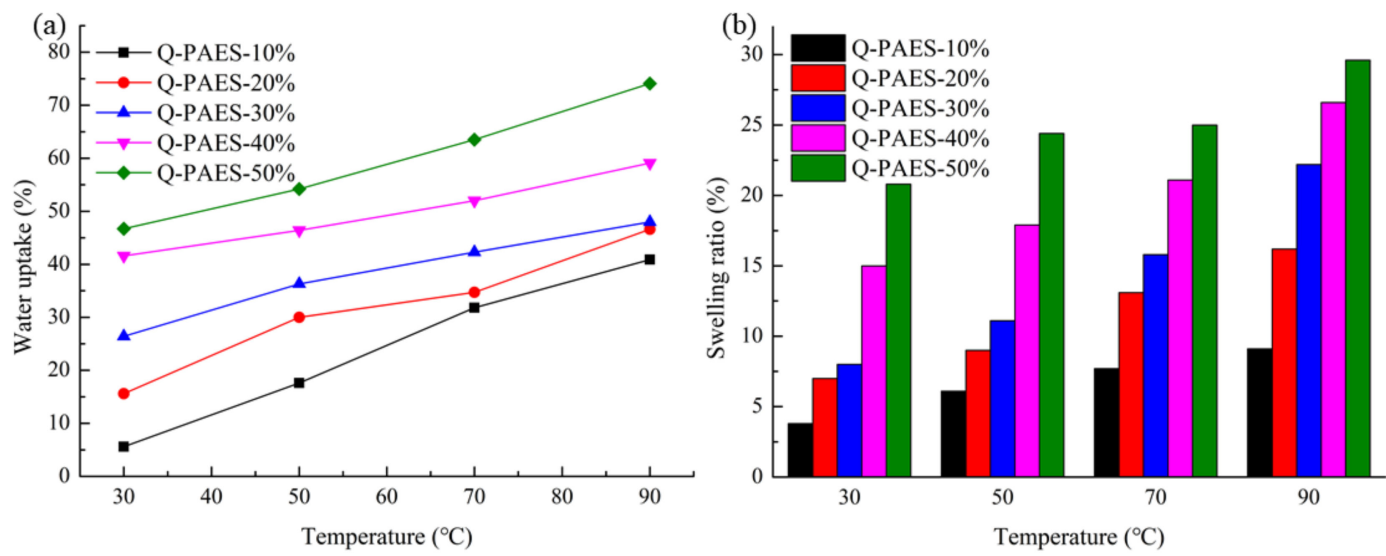

Figure 6. (a) Water uptake of fabricated membrane and (b) swelling ratio of Q-PAESs. 


\subsection{Morphology}

The surface morphology of the AEM can impact the performance of the membrane. In particular, some researchers have reported that the formation of ion channels due to the hydrophilic and hydrophobic nano phase separation improves ion conductivity of the membrane [28]. The surface morphology of the fabricated Q-PAESs was observed via AFM, and the images are shown in Figure 7. No significant phase separation was seen in Q-PAES-10\%, Q-PAES-20\% and Q-PAES-30\%. However, Q-PAES- $40 \%$ and Q-PAES- $50 \%$ possessed the nano phase separation in which bright and dark parts are clearly distinguished. Hydrophilic regions appear in darker region because the quaternary ammonium groups used as functional groups absorb water, and vice versa. As shown in the figure, as the DB value increases, the substitution of the quaternary ammonium salt also increases, so it can be seen that the nano phase separation is apparent. As revealed from Figure 7e,j, the average size of hydrophilic domains might be a $100 \mathrm{~nm}$ in case of Q-PAES-50\% membrane.
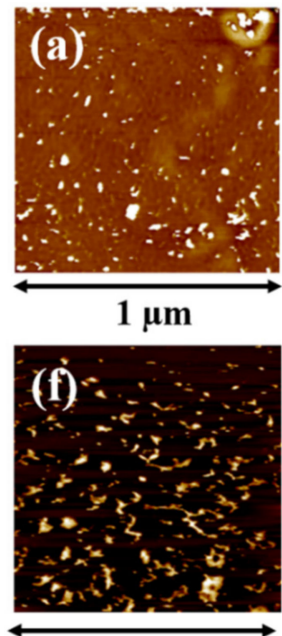

$500 \mathrm{~nm}$

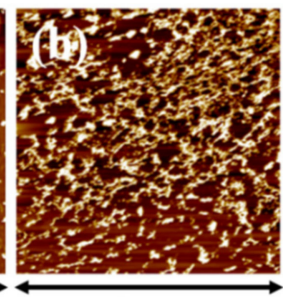

$1 \mu \mathrm{m}$

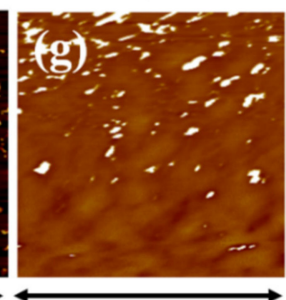

$500 \mathrm{~nm}$

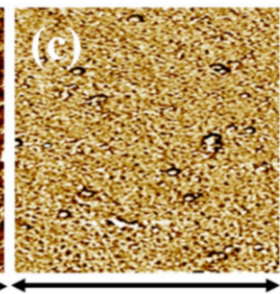

$1 \mu \mathrm{m}$

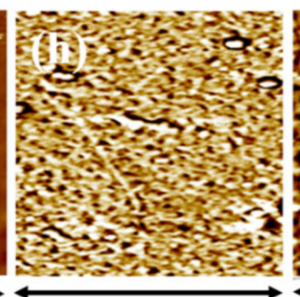

$500 \mathrm{~nm}$

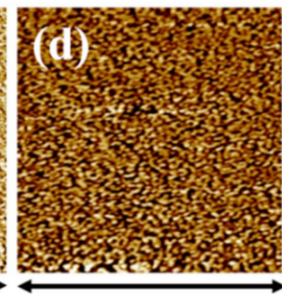

$1 \mu \mathrm{m}$

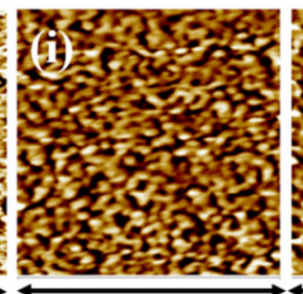

$500 \mathrm{~nm}$

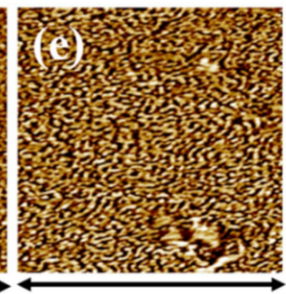

$1 \mu \mathrm{m}$

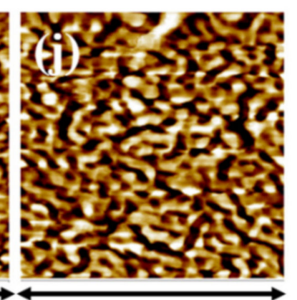

$500 \mathrm{~nm}$

Figure 7. AFM phase images of (a,f) Q-PAES-10\%, (b,g) Q-PAES-20\%, (c,h) Q-PAES-30\%, (d,i) Q-PAES-40\%, (e,j) Q-PAES-50\%.

\subsection{Ion Conductivity and Activation Energy}

Ionic conductivity is a dominant factor which determine the overall performance of the anion exchange membranes. In general, ionic conductivity of membranes differs according to the several of complex factors, such as the type of polymer and the type of functional group $[29,30]$. Conductivity of the fabricated Q-PAES was quantified at diversified temperatures under $100 \%$ relative humidity (RH). The ionic conductivity of Q-PAES was varied due to the increased mobility of hydroxide ions when increasing the temperature. Unsurprisingly, as the DB increased, the ion conductivity value tended to increase. In particular, there is a big difference between Q-PAES-20\% and Q-PAES-30\%, which can be attributed to the phase separation property of Q-PAES- $30 \%$ as shown in the AFM image. At $90{ }^{\circ} \mathrm{C}$, Q-PAES-20\%, Q-PAES-30\%, and Q-PAES-50\% were displayed ionic conductivities of 11.6 , 24.4 and $51.8 \mathrm{mS} / \mathrm{cm}$ respectively (Figure 8a). On the basis of these abovementioned results, it could be concluded that the phase separation property of membrane causes the ionic conductivity to vary greatly. Arrhenius plots using ion conductivity showed that Q-PAES- $50 \%$ had the highest activation value of $22.2 \mathrm{~kJ} / \mathrm{mol}$ while Q-PAES-50\% had the lowest value of $13.2 \mathrm{~kJ} / \mathrm{mol}$ (Figure $8 \mathrm{~b}$ ). 
(a)

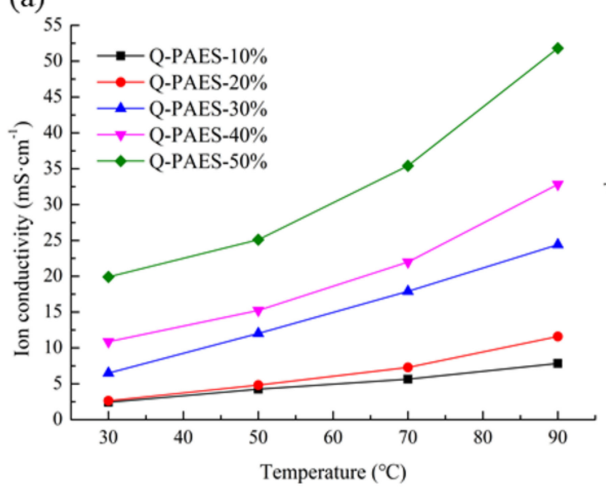

(b)

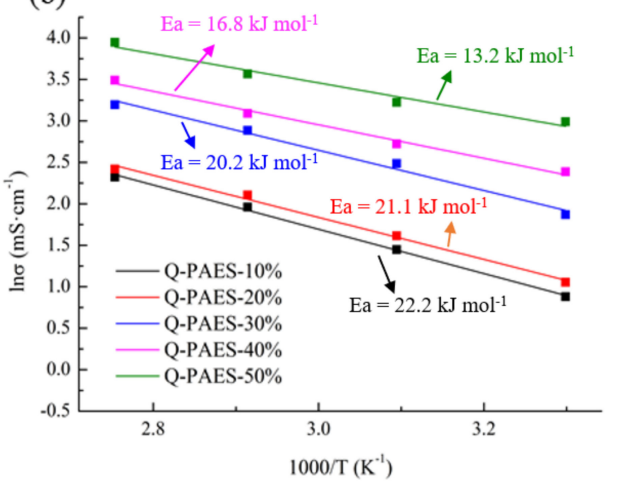

Figure 8. (a) Ion conductivity of Q-PAES membranes and (b) Arrhenius plot of Q-PAES membranes at diversified temperatures with $100 \% \mathrm{RH}$.

\subsection{Alkaline Stability and Single Cell Activity}

The stability of the anion exchange membrane under alkaline environment is one of the problems that $\mathrm{AFC}$ must solve. In a typical $\mathrm{AFC}$, the higher $\mathrm{pH}$ values of hydroxide ions under elevated operating temperature promote the decomposition of the quaternary ammonium groups in the polymer matrix which in turn higher the vulnerability of the membrane [31,32]. Alkaline stability of prepared Q-PAES membranes was examined by ${ }^{1} \mathrm{H}-\mathrm{NMR}$ analysis, after immersing the samples in $1 \mathrm{M} \mathrm{KOH}$ solution at $60^{\circ} \mathrm{C}$ for $1000 \mathrm{~h}$. In Figure 9, the peak measured at $3 \mathrm{ppm}$ is due to the $\mathrm{C}-\mathrm{N}$ binding and the area before and afterward the alkaline stability operation was compared. Nearly all functional groups remained undecomposed in Q-PAES- $10 \%$, whereas only $42 \%$ of functional groups remained in Q-PAES- $50 \%$. Therefore, as the degree of quaternization increased, it was found that the decomposition of the functional group proceeded further in alkaline environment. It can be concluded that since the functional sides of membranes act as an electron withdrawal group that lowers the electron density of the polymer main chain, as a consequence, the decomposition caused by nucleophilic hydroxide ion occurred more easily. The single cell activity of notable Q-PAES- $50 \%$ was quantified. The detailed protocols for creation of membrane electrode assembly and operation of fuel cell can be observed in reference [33]. As revealed from Figure 10a, the considerable power output of $64 \mathrm{~mW} / \mathrm{cm}^{2}$ was reached. Nevertheless, the Q-PAES-50\% can stable be up to $18 \mathrm{~h}$ and lose the voltage after $18 \mathrm{~h}$ (Figure 10b). If additional work put forward in future, the power output and durability of membrane could be improved. According to Table 2 given, the Q-PAES-50\% revealed considerable power output, but that is lower than other reported electrolytes.

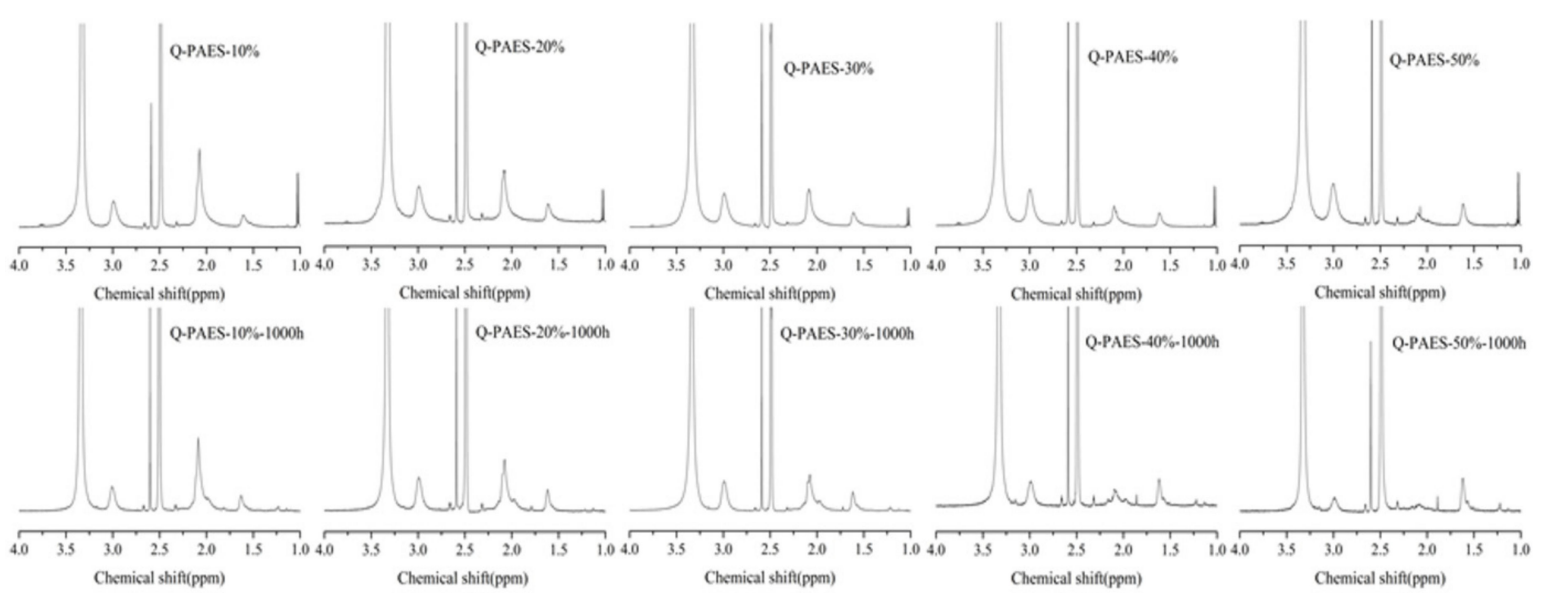

Figure 9. ${ }^{1} \mathrm{H}-\mathrm{NMR}$ data of Q-PAES membranes before and after alkaline stability operation in $1 \mathrm{M}$ $\mathrm{KOH}$ solution at $70^{\circ} \mathrm{C}$ for $1000 \mathrm{~h}$. 

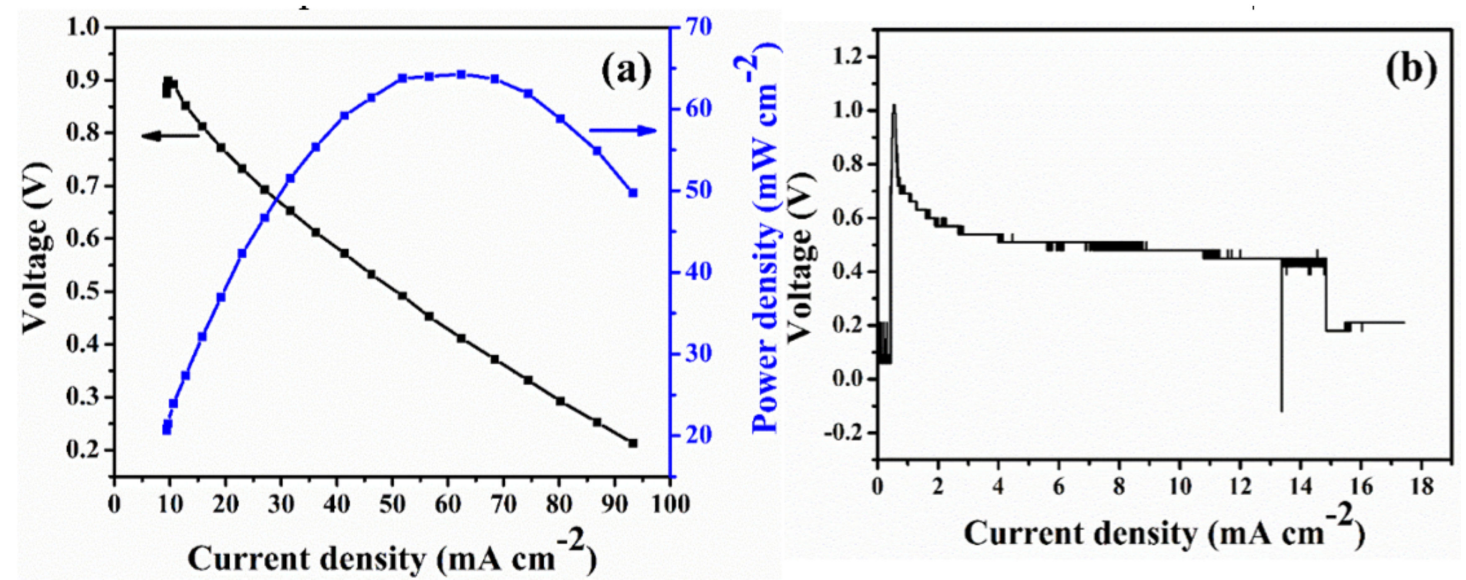

Figure 10. (a) Single fuel cell operation curve and (b) durability plot of Q-PAES-50\% quantified at $60{ }^{\circ} \mathrm{C}$ and $100 \%$ RH. (Catalyst of anode and cathode was $\mathrm{Pt} / \mathrm{C}, 0.3 \mathrm{mg} / \mathrm{cm}^{2}$; humidified hydrogen $(100 \mathrm{~mL})$ and oxygen $(300 \mathrm{~mL})$ were passed to anode and cathode).

Table 2. Comparison table of Q-PAES-50\% with other reported membranes.

\begin{tabular}{|c|c|c|c|c|}
\hline $\operatorname{AEM}^{a}$ & $\begin{array}{c}\text { Maximum Power } \\
\text { Output }\left(\mathrm{mW} / \mathrm{cm}^{2}\right) \\
{\left[\operatorname{RH}^{\mathbf{b}}(\%) ; \operatorname{Tem}^{\mathrm{c}}\left({ }^{\circ} \mathrm{C}\right)\right]}\end{array}$ & $\begin{array}{c}\text { Hydroxide } \\
\text { Conductivity } \\
(\mathrm{mS} / \mathrm{cm})\left[\mathrm{RH}^{\mathrm{b}}(\%)\right. \\
\left.\operatorname{Tem}^{\mathrm{c}}\left({ }^{\circ} \mathrm{C}\right)\right]\end{array}$ & IEC (mmol/g) & Ref. \\
\hline A-PEI-8 e & - & $44.2[100 ; 90]$ & 1.23 & [31] \\
\hline AEM-3 ${ }^{d}$ & $152[70 ; 50]$ & $140[100 ; 85]$ & 2.89 & [34] \\
\hline $\begin{array}{c}5 \% \\
\mathrm{IL}^{\mathrm{f}}-\mathrm{TnT}^{\mathrm{g}} / \mathrm{QAPSU} \mathrm{h}^{-}\end{array}$ & $302[100 ; 60]$ & $20.8[100 ; 30]$ & 1.93 & [35] \\
\hline QBz ${ }^{\mathrm{i}-P E E K}-76.0 \%$ & $391[100 ; 70]$ & $155[100 ; 60]$ & 1.73 & [36] \\
\hline QN-PAEK $^{\mathrm{j}} / \mathrm{rGO}^{\mathrm{k}} 5.0 \mathrm{wt} \%$ & - & $116.8[100 ; 90]$ & 1.32 & [18] \\
\hline bQPAES-x7y32-1 & - & $86.3[100 ; 80]$ & 1.15 & [37] \\
\hline Q-PAES- $50 \%$ & $64[100 ; 60]$ & $51.8[100 ; 90]$ & 1.87 & current work \\
\hline
\end{tabular}

a Anion exchange membrane; ${ }^{\mathrm{b}}$ Relative humidity; ${ }^{\mathrm{c}}$ Temperature; ${ }^{\mathrm{d}}$ Cross linked polymer membranes prepared from tetraalkylammonium-functionalized norbornene derivatives; ${ }^{\mathrm{e}}$ Alkalized poly(ether imide)s; ${ }^{\mathrm{f}}$ Ionic liquid (1-Methyl-3-(3-trimethoxysilylpropyl) imidazolium chloride); ${ }^{\mathrm{g}}$ Titanate nano tubes; ${ }^{\mathrm{h}}$ Quaternised polysulfone; ${ }^{i}$ Benzylation modification of poly(ether ether ketone); ${ }^{j}$ Quaternized poly(arylene ether ketone); ${ }^{k}$ Reduced graphene oxide; ${ }^{1}$ Benzyl-quaternary ammonium groups tethered poly(arylene ether sulfone) block copolymer ionomers.

\section{Conclusions}

In this study, we have successfully created AEMs with high conductivity and improved alkaline stability. Additionally, we examined the microphase separation and characteristics of polymers with different quaternization degree by controlling the DB value via controlling the amount of NBS. The synthesized polymers were analyzed by ${ }^{1} \mathrm{H}-\mathrm{NMR}$ and FT-IR to confirm the reaction was successfully carried out. Solubility measurements showed that each polymer was soluble in most polar aprotic solvents, but not in polar protic solvents such as water and methanol. In addition, only Q-PAES was partially dissolved in DMSO. This was assumed to be caused by the charged portion of Q-PAES. The thermal properties of the polymers were analyzed by TGA and DSC, and the decomposition of the functional groups was confirmed to be decomposed at about $180^{\circ} \mathrm{C}$. In the case of water moisture content and expansion rate, both tended to increase as the degree of quaternization reaction increased. Observation through the AFM image to analyze the surface of the membrane showed a marked phase separation from Q-PAES- $40 \%$. Ion conductivity of the synthesized anion exchange membrane was measured at various temperatures under $100 \%$ relative humidity. At $90{ }^{\circ} \mathrm{C}$, Q-PAES- $10 \%$ exhibited a low conductivity of $11.1 \mathrm{mS} / \mathrm{cm}$ while Q-PAES- $50 \%$ possessed a higher value of $51.8 \mathrm{mS} / \mathrm{cm}$. Alkaline stability test shows that the higher the quaternization degree, the sharper the decrease in stability under alkaline environment. This is owning to the reduction in electron density of polymer main chain which due to the substitution of functional groups, and thus cause the facile decomposition of membrane by nucleophiles. Therefore, the high degree of quaternization reaction of 
the anion exchange membrane may form ion channels, which may exhibit high performance. However, it is imperative to properly control the quaternization reaction of the polymer because it may affect the physical and chemical stability of the membrane.

Author Contributions: The J.H.K. proceeded to design and analyze the data for the experiment; M.V., A.R.K. supported the analysis of the data and wrote the paper; and D.J.Y. performed reviewing and editing. All authors have read and agree to the published version of the manuscript.

Funding: This work was supported by the Korea Institute of Energy Technology Evaluation and Planning (KETEP) and the Ministry of Trade, Industry \& Energy (MOTIE) of the Republic of Korea (No. 20184030202210). This work was supported by grants from the Medical Research Center Program (NRF-2017R1A5A2015061) through the National Research Foundation (NRF), which is funded by the South Korean government (MSIP).

Conflicts of Interest: The authors declare no conflict of interest.

\section{References}

1. Liu, J.; Yan, X.; Gao, L.; Hu, L.; Wu, X.; Dai, Y.; Ruan, X.; He, G. Long-branched and densely functionalized anion exchange membranes for fuel cells. J. Membr. Sci. 2019, 581, 82-92.

2. Lee, K.H.; Chu, J.Y.; Kim, A.R.; Yoo, D.J. Enhanced performance of a sulfonated poly(arylene ether ketone) block copolymer bearing pendant sulfonic acid groups for polymer electrolyte membrane fuel cells operating at 80\% relative humidity. ACS Appl. Mater. Interfaces 2018, 10, 20835-20844.

3. Lai, A.N.; Wang, L.S.; Lin, C.X.; Zhuo, Y.Z.; Zhang, Q.G.; Zhu, A.M.; Liu, Q.L. Phenolphthalein-based poly(arylene ether sulfone nitrile)s multiblock copolymers as anion exchange membranes for alkaline fuel cells. ACS Appl. Mater. Interf. 2015, 7, 8284-8292. [CrossRef]

4. Mohanty, A.D.; Lee, Y.B.; Zhu, L.; Hickner, M.A.; Bae, C. Anion exchange fuel cell membranes prepared from C-H borylation and Suzuki coupling reactions. Macromolecules 2014, 47, 1973-1980.

5. Yang, Q.; Li, L.; Lin, C.X.; Gao, X.L.; Zhao, C.H.; Zhang, Q.G.; Zhu, A.M.; Liu, Q.L. Hyperbranched poly(arylene ether ketone) anion exchange membranes for fuel cells. J. Membr. Sci. 2018, 560, 77-86.

6. Kwon, S.; Rao, A.H.N.; Kim, T.H. Anion exchange membranes based on terminally crosslinked methyl morpholinium-functionalized poly(arylene ether sulfone)s. J. Power Sources 2017, 375, 421-432.

7. Zhuo, Y.Z.; Lai, A.L.; Zhang, Q.G.; Zhu, A.M.; Ye, M.L.; Liu, Q.L. Enhancement of hydroxide conductivity by grafting flexible pendant imidazolium groups into poly(arylene ether sulfone) as anion exchange membranes. J. Mater. Chem. A. 2015, 3, 18105-18114. [CrossRef]

8. Lin, X.; Wu, L.; Liu, Y.; Ong, A.L.; Poynton, S.D.; Varcoe, J.R.; Xu, T. Alkali resistant and conductive guanidinium-based anion-exchange membranes for alkaline polymer electrolyte fuel cells. J. Power Sources 2012, 217, 373-380. [CrossRef]

9. Lin, X.; Liang, X.; Poynton, S.D.; Varcoe, J.R.; Ong, A.L.; Ran, J.; Li, Y.; Li, Q.; Xu, T. Novel alkaline anion exchange membranes containing pendant benzimidazolium groups for alkaline fuel cells. J. Membr. Sci. 2013, 443, 193-200. [CrossRef]

10. Qiao, J.; Fu, J.; Liu, L.; Zhang, J.; Xie, J.; Li, G. Synthesis and properties of chemically cross-linked poly(vinyl alcohol)-poly(acrylamide-co-diallyldimethylammonium chloride) (PVA-PAADDA) for anion-exchange membranes. Solid State Ion. 2012, 214, 6-12. [CrossRef]

11. Zhang, J.; Qiao, J.; Jiang, G.; Liu, L.; Liu, Y. Cross-linked poly(vinyl alcohol)/poly(diallyldimethylammonium chloride) as anion-exchange membrane for fuel cell applications. J. Power Sources 2013, 240, 359-367. [CrossRef]

12. Pan, Z.F.; An, L.; Zhao, T.S.; Tang, Z.K. Advances and challenges in alkaline anion exchange membrane fuel cells. Prog. Energy Combust. Sci. 2018, 66, 141-175. [CrossRef]

13. Chen, W.; Yan, X.; Wu, X.; Huang, S.; Luo, Y.; Gong, X.; He, G. Tri-quaternized poly(ether sulfone) anion exchange membranes with improved hydroxide conductivity. J. Membr. Sci. 2016, 514, 613-621.

14. Kim, Y.; Moh, L.C.H.; Swager, T.M. Anion exchange membranes: Enhancement by addition of unfunctionalized triptycene poly(ether sulfone)s. ACS Appl. Mater. Interfaces 2017, 9, 42409-42414.

15. Zheng, J.; Zhang, Q.; Qian, H.; Xue, B.; Li, S.; Zhang, S. Self-assembly prepared anion exchange membranes with high alkaline stability and organic solvent resistance. J. Membr. Sci. 2017, 522, 159-167. [CrossRef] 
16. Fang, J.; Wu, Y.; Zhang, Y.; Lyu, M.; Zhao, J. Novel anion exchange membranes based on pyridinium groups and fluoroacrylate for alkaline anion exchange membrane fuel cells. Int. J. Hydrog. Energy 2015, 40, 12392-12399. [CrossRef]

17. Lin, C.X.; Zhuo, Y.Z.; Hu, E.N.; Zhang, Q.G.; Zhu, A.M.; Liu, Q.L. Crosslinked side-chain-type anion exchange membranes with enhanced conductivity and dimensional stability. J. Membr. Sci. 2017, 539, 24-33. [CrossRef]

18. Chu, J.Y.; Lee, K.H.; Kim, A.R.; Yoo, D.J. Graphene-mediated organic-inorganic composites with improved hydroxide conductivity and outstanding alkaline stability for anion exchange membranes. Compos. Pt. B Eng. 2019, 164, 324-332. [CrossRef]

19. Lee, K.H.; Chu, J.Y.; Kim, A.R.; Yoo, D.J. Facile fabrication and characterization of improved proton conducting sulfonated poly(arylene biphenylether sulfone) blocks containing fluorinated hydrophobic units for proton exchange membrane fuel cell applications. Polymers 2018, 10, 1367.

20. Zhang, N.; Zhao, C.; Ma, W.; Wang, S.; Wang, B.; Zhang, G.; Li, X.; Na, H. Macromolecular covalently cross-linked quaternary ammonium poly(ether ether ketone) with polybenzimidazole for anhydrous high temperature proton exchange membranes. Polym. Chem. 2014, 5, 4939-4947.

21. Li, X.; Wang, L.; Cheng, S. Investigation on structure and properties of anion exchange membranes based on tetramethylbiphenol moieties containing copoly(arylene ether)s. J. Appl. Polm. Sci. 2015, 132, 41525. [CrossRef]

22. Zhang, N.; Wang, B.; Zhao, C.; Wang, S.; Zhang, Y.; Bu, F.; Cui, Y.; Li, X.; Na, H. Quaternized poly(ether ether ketone)s doped with phosphoric acid for high-temperature polymer electrolyte membrane fuel cells. J. Mater. Chem. A 2014, 2, 13996-14003. [CrossRef]

23. Wang, B.; Sun, W.; Bu, F.; Li, X.; Zhao, C. Comparison of alkaline stability of benzyltrimethylammonium, benzylmethylimidazolium and benzyldimethylimidazolium functionalized poly(arylene ether ketone) anion exchange membranes. Int. J. Hydrog. Energy 2016, 41, 3102-3112. [CrossRef]

24. Zhao, C.; Ma, W.; Sun, W.; Na, H. Preparation of anion exchange membrane based on homogeneous quaternization of bromomethylated poly(arylene ether sulfone). J. Appl. Polym. Sci. 2014, 131, 40256.

25. Xu, Y.; Yang, J.; Ye, N.; Teng, M.; He, R. Modification of poly(aryl ether ketone) using imidazolium groups as both pendants and bridging joints for anion exchange membranes. Eur. Polym. J. 2015, 73, 116-126. [CrossRef]

26. Li, X.; Tao, J.; Nie, G.; Wang, L.; Li, L.; Liao, S. Cross-linked multiblock copoly(arylene ether sulfone) ionomer/nano- $\mathrm{ZrO}_{2}$ composite anion exchange membranes for alkaline fuel cells. RSC Adv. 2014, 4, 41398-41410. [CrossRef]

27. Kim, A.R.; Vinothkannan, M.; Yoo, D.J. Sulfonated-fluorinated copolymer blending membranes containing SPEEK for use as the electrolyte in polymer electrolyte fuel cells (PEFC). Int. J. Hydrog. Energy 2017, 42, 4349-4365. [CrossRef]

28. Dong, X.; Lv, D.; Zheng, J.; Xue, B.; Bi, W.; Li, S.; Zhang, S. Pyrrolidinium-functionalized poly(arylene ether sulfone)s for anion exchange membranes: Using densely concentrated ionic groups and block design to improve membrane performance. J. Membr. Sci. 2017, 535, 301-311.

29. Hao, J.; Gao, X.; Jiang, Y.; Xie, F.; Shao, Z.; Yi, B. Fabrication of N1-butyl substituted 4,5-dimethyl-imidazole based crosslinked anion exchange membranes for fuel cells. RSC Adv. 2017, 7, 52812-52821.

30. Vinothkannan, M.; Kim, A.R.; Gnana, K.G.; Yoo, J.M.; Yoo, D.J. Toward improved mechanical strength, oxidative stability and proton conductivity of an aligned quadratic hybrid (SPEEK/FPAPB/ $\mathrm{Fe}_{3} \mathrm{O}_{4}$-FGO) membrane for application in high temperature and low humidity fuel cells. RSC Adv. 2017, 7, 39034-39048. [CrossRef]

31. Oh, B.H.; Kim, A.R.; Yoo, D.J. Profile of extended chemical stability and mechanical integrity and high hydroxide ion conductivity of poly(ether imide) based membranes for anion exchange membrane fuel cells. Int. J. Hydrog. Energy 2019, 44, 4281-4292. [CrossRef]

32. Lin, B.; Qiu, L.; Qiu, B.; Peng, Y.; Yan, F. A soluble and conductive polyfluorene ionomer with pendant imidazolium groups for alkaline fuel cell applications. Macromolecules 2011, 44, 9642-9649.

33. Chu, J.Y.; Lee, K.H.; Kim, A.R.; Yoo, D.J. Study on the chemical stabilities of poly(arylene ether) random copolymers for alkaline fuel cells: effect of main chain structures with different monomer units. ACS Sust. Chem. Eng. 2019, 7, 2077-20087. [CrossRef]

34. Wang, C.; Mo, B.; He, Z.; Shao, Q.; Pan, D.; Wujick, E.; Guo, J.; Xie, X.; Xie, X.; Guo, Z. Crosslinked norbornene copolymer anion exchange membrane for fuel cells. J. Membr. Sci. 2018, 556, 118-122. 
35. Elumalai, V.; Sangeetha, D. Synergic effect of ionic liquid grafted titanate nanotubes on the performance of anion exchange membrane fuel cell. J. Power Sources 2019, 412, 586-596.

36. Zhang, Z.; Xiao, X.; Yan, X.; Liang, X.; Wu, L. Highly conductive anion exchange membranes based on one-step benzylation modification of poly(ether ether ketone). J. Membr. Sci. 2019, 574, 205-211.

37. Zhang, X.; Shi, Q.; Chen, P.; Zhou, J.; Li, S.; Xu, H.; Chen, X.; An, Z. Block poly(arylene ether sulfone) copolymers tethering aromatic side-chain quaternary ammonium as anion exchange membranes. Polym. Chem. 2018, 9, 699. [CrossRef]

(C) 2020 by the authors. Licensee MDPI, Basel, Switzerland. This article is an open access article distributed under the terms and conditions of the Creative Commons Attribution (CC BY) license (http://creativecommons.org/licenses/by/4.0/). 